\title{
PENGARUH KUALITAS PRODUK MURABAHAH, HARGA, DAN \\ KUALITAS PELAYANAN TERHADAP KEPUASAN NASABAH \\ DI BAITUL MAAL WAT TAMWIL NURUL UMMAH \\ NGASEM BOJONEGORO
}

\author{
Moch. Zaenal Azis Muctharom \\ Sekolah Tinggi Agama Islam Al Hikmah Tuban \\ azies1922@gmail.com
}

\begin{abstract}
This study aims to clearly describe the quality of murabahah, haraga, service quality and customer satisfaction at Baitul Maal Wat Tamwil Nurul Ummah Ngasem-Bojonegoro. The second objective is to examine the significant influence of murabaha product quality on customer satisfaction. The third objective is to examine the significant effect of Price on customer satisfaction. The fourth objective is to examine the influence (quality of murabaha products, Price and Service Quality) silmutanously on customer satisfaction. The fifth objective is to test the most dominant (murabaha product quality, price and service quality to customer satisfaction). The study population is the Customer at Baitul Maal Wat Tamwil Nurul Ummah Ngasem-Bojonegoro. Sampling amounted to 56 respondents. Analysis of the study was conducted using data collection methods, questionnaires, interviews, observation and documentation. Data analysis techniques using SPSS 19.0 with the stages are (1) validity and reliability test (2) multiple regression analysis (3) hypothesis testing is t test and f test. Descriptive analysis results show: The results of the study indicate that there is a significant influence between product quality on customer satisfaction, while price has no significant effect on customer satisfaction and service quality has no significant effect on customer satisfaction. Between product quality, price and quality services, the most dominant influence on customer satisfaction in KJKS BMT Nurul Ummah Ngasem-Bojonegoro is product quality.
\end{abstract}

Keywords: Murabaha product quality, price, service quality and customer satisfaction

\section{Pendahuluan}

Dalam perkembangan ekonomi saat ini, bisnis keuangan terutama lembaga keuangan syari'ah banyak diminati oleh masyarakat. Masyarakat beranggapan bahwa lembaga keuangan yang berlandaskan azas syari'ah akan lebih aman dan nyaman karena menggunakan sistem bagi hasil dan menggunakan akad-akad 
yang sesuai dengan syari'at islam. Dengan landasan ini masyarakat semakin mempercayai keuangannya dengan lembaga keuangan syari'ah. Namun yang harus diperhatikan masyarakat juga memperhatikan kualitas dari lembaga keuangan syari'ah tersebut apakah sudah seperti yang mereka inginkan, missal dalam Kepuasan adalah tingkat perasaan seseorang setelah membandingkan kinerja (atau hasil) yang dia rasakan dibandingkan dengan harapannya ${ }^{1}$. Dapat ditarik kesimpulan bahwa tingkat kepuasan merupakan fungsi dari perbedaan antara kinerja yang dirasakan dengan harapan.

\section{Kualitas Produk}

Salah satu nilai utama yang diharapkan oleh pelanggan dari produsen adalah kualitas produk dan jasa yang tertinggi. Menurut American Society for Quality Contrl $^{2}$, kualitas adalah keseluruhan ciri serta sifat suatu produk atau pelayanan yang berpengaruh pada kemampuannya untuk memuaskan kebutuhan yang dinyatakan atau tersirat.

\section{Pengertian produk}

Produk adalah suatu himpunan dari atribut - atribut fisik atau abstrak yang mungkinakan diterima pembeli sebagai pemenuhan kebutuhannya. Sedangkan menurut Kotler produk adalah setiap tawaran yang dapat memuaskan kebutuhan dan keinginan. ${ }^{3}$ Dari pengertian di Atas juga dijelaskan mengenai jenis - jenis produk yang dapat diuraikan sebagai berikut:

a. Barang = barang - barang fisik merupakan bagian yang terbesar dari produksi dan usaha pemasaran.

b. $\quad$ Jasa $=$ jasa dalam kehidupan saat ini sangat meningkat proporsinya seiring dengan perekonomian yang semakin berkembang.

\footnotetext{
${ }^{1}$ Rambat Lupiyoadi dan A. Hamdani, Manajemen Pemasaran Jasa Edisi2, (Jakarta: Salemba Empat, 2006), 52. 
Sedangkan menurut Garvin yang dikutip oleh Gaspersz ${ }^{4}$, untuk menentukan kualitas produk, dapat dimasukkan ke dalam dimensi, yaitu:

a. Reliability = berkaitan dengan probabilitas atau kemungkinan.

b. Conformance $=$ berkaitan dengan tingkat kesesuaian .

c. Service Ability = karakteristik yang berkaitan dengan kecepatan.

\section{Pengertian Produk dalam Islam}

Produksi adalah sebuah proses yang telah terlahir di muka bumi ini semenjak manusia menghuni planet ini. Beberapa ahli ekonomi islam memberikan definisi yang berbeda mengenai pengertian produksi, meskipun substansinya sama. Berikut pengertian produksi menurut para ekonomi muslim kontemporer.

Produksi yang Islami menurut Siddiqi adalah penyediaan barang dan jasa dengan memperhatikan nilai - nilai keadilan dan kebijakan atau manfaat (mashlahah) bagi masyarakat. Ayat yang berkaitan dengan produksi terdapat dalam Surat an-nahal ayat 67, yang memiliki makna "Dan dari buah korma dan anggur, kamu buat minimuman yang memabukkan dan rezki yang baik. Sesunggguhnya pada yang demikian itu benar-benar terdapat tanda (kebesaran Allah) bagi orang yang memikirkan" (Surat an-nahl ayat 67). ${ }^{5}$

Maksud dari ayat dia atas manfaat buah-buahan yang dapat dimakan dan dapat menghasilkan minuman. Hanya saja minuman tersebut dapat berubah menjadi sesuatu yang buruk karena memabukan.

\section{Harga}

\section{Pengertian Harga}

Harga menurut Kotler dan Amstrong adalah sejumlah uang yang ditukarkan untuk sebuah produk atau jasa. Namun dalam dasawarsa terakhir ini, faktor - faktor lain selain harga telah beralih menjadi relatif lebih penting dalam proses pembelian, yang mencirikan harga yaitu :

a) Keterjangkauan harga.

b) Kesesuaian harga dengan kualitas produk.

\footnotetext{
${ }^{4}$ Garvin dan Umar, Husein, Riset Pemasaran dan Perilaku Konsumen, (Jakarta : PT Gramedia Pustaka Utama, 2003), 233.

${ }^{5}$ Al-qur'an surat16: 67.
} 
c) Kesesuaian harga dengan manfaat.

\section{Pengertian harga dalam islam}

Harga merupakan sesuatu kesepakatan mengenai transaksi jual beli barang /jasa di mana kesepakatan tersebut diridai oleh kedua belah pihak. Harga tersebut haruslah direlakan oleh kedua belah pihak dalam akad, baik lebih sedikit, lebih besar, atau sama dengan nilai barang/ jasa yang ditawarkan oleh pihak penjual kepada pihak pembeli. Anas bin malik menuturkan bahwa pada masa Rasullah Saw pernah terjadi harga - harga melambung tinggi. Para sahabat lalu berkata kepada rasul. “ya rasul tetapkanlah harga demi kami”. Rasullah menjawab :

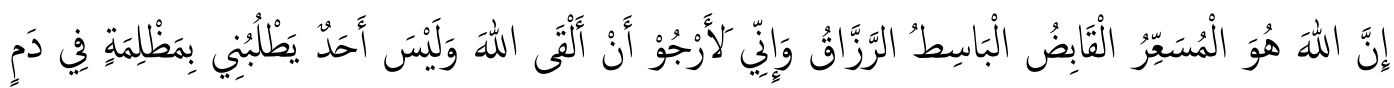
وَلَا مَالٍ

Sesungguhnya Allah zat yang menentukan harga,yang menahan,yang mengeluarkan, dan yang maha memberi rizki. Sungguh aku berharap dapat menjumpai Allah tanpa ada serang pun yang menuntutku atas kezoliman yang aku lakukan dalam masalah darah dan tidak juga masalah harta". ( HR Abu dawud,ibn majah dan at-trimidzi ). ${ }^{6}$

Para ulama minyumpulkan dari hadist tersebut bahwa haram bagi penguasa untuk menentukan harga barang-barang karena hal ituadalah sumber kedzaliman.

\section{Kualitas Pelayanan}

\section{Pengertian Kualitas Pelayanan}

Kualitas pelayanan sangat bergantung pada tiga hal, yaitu sistem, teknologi dan manusia. Faktor manusia memegang kontribusi terbesar sehingga kualitas pelayanan lebih sulit ditiru dibandingkan dengan kualitas produk dan harga.

${ }^{6} \mathrm{HR}$ Abu dawud,ibn majah dan at-trimidzi.., 
Menurut Fandy Tjiptono dan Gregorius Chandra mengemukakan bahwa "kualitas pelayanan sebagai ukuran seberapa bagus tingkat layanan yang diberikan mampu sesuai dengan ekspektasi pelanggan". 7

\section{Indikator Kualitas Pelayanan}

Konsep kualitas pelayanan persepsi konsumen terhadap lima dimensi fisik dan kinerja layanan, Parasuraman, et.al., dalam Kotler dan Keller menyimpulkan bahwa ada lima dimensi yang dipakai untuk mengukur kualitas pelayanan, yaitu: ${ }^{8}$

a. Reliabilitas (reliability), berkaitan dengan kemampuan.

b. Daya tanggap (responsiveness), berkenaan dengan kesediaan dan kemampuan penyedia layanan.

c. Empati (empathy), berarti bahwa perusahaan memahami masalah para pelanggannya dan bertindak demi kepentingan pelanggan.

\section{Kualitas Pelayanan Dalam Perspektif Islam}

Islam mengajarkan bila ingin memberikan hasil usaha baik berupa barang maupun pelayanan / jasa hendaknya memberikan yang berkualitas, jangan memberikan yang buruk atau tidak berkualitas kepada orang lain. Seperti dijelaskan dalam Al-Quran surat Al-Baqarah ayat 267

Hai orang-orang yang beriman, nafkahkanlah (di jalan Allah) sebagian dari hasil usahamu yang baik-baik dan sebagian dari apa yang Kami keluarkan dari bumi untuk kamu. dan janganlah kamu memilih yang buruk-buruk lalu kamu menafkahkan daripadanya, Padahal kamu sendiri tidak mau mengambilnya melainkan dengan memincingkan mata terhadapnya. dan ketahuilah, bahwa Allah Maha Kaya lagi Maha Terpuji. (Al-Quran surat Al-Baqarah ayat 267) ${ }^{9}$.

Dalam ekonomi konvensional, pilihan didasarkan atas selera pribadi masing-masing. Manusia boleh mempertimbangkan tuntunan agama, boleh juga mengabaikan. Sedangkan dalam ekonomi Islam, keputusan pilihan ini tidak dapat dilakukan semaunya saja, semua perilaku harus dipandu oleh Allah lewat AlQur'an dan Hadis.

\footnotetext{
${ }^{7}$ Tjiptono Fandy dan Gregorius Chandra, Service, Citra Wisata dan Satisfaction, (Yogyakarta: Andi, 2005), 121.

${ }^{8}$ Parasuraman, et.al.dalam Philip Kotler dan Kevin Lane Keller, Manajemen Pemasaran, 56.

${ }^{9} \mathrm{Al}$-qur'an surat 2: 267.
} 


\section{Pengertian Kepuasan Nasabah}

\section{Pengertian Kepuasan}

Kepuasan merupakan tigkat kepuasan konsumen yang diperoleh setelah konsumen melakukan atau menikmati sesuatu. Dengan demikian dapat diartikan bahwa kepuasan konsumen (nilai harapan) dengan situasi yang diberikan perusahaan di dalam usaha memenuhi harapan konsumen. Bisnis tidak akan berjalan tanpa adanya konsumen yang menggunakan produk atau jasa yang ditawarkan oleh produsen. ${ }^{10}$

\section{Kepuasan Nasabah Menurut Perspektif Islam}

Berbeda dengan konsep ekonomi konvensional yang menyatakan bahwa kepuasan konsumen terjadi bila kebutuhan yang bersifat fisik telah terpenuhi, dalam islam, kepuasan terjadi manakala telah terpenuhinya kebutuhan fisik maupun non fisik seseorang. ${ }^{11}$. Untuk mencapai tingkat kepuasan dalam kegiatan konsumsi, islam memberikan panduan yaitu :

Semua anggota perusahaan mengharapkan pelayanaan yang baik agar anggotanya merasakan puas yang dya dapat saat membeli produk tersebut. Seperti yang diriwayatkan At-Tirmiidzi,Ahmad Dan Al-Baghawy :

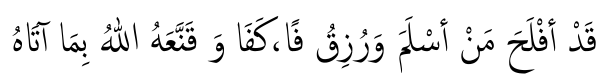

Beruntunglah orang yang memasrahkan diri, dilimpahi rizki yang sekedar mencukupi dan diberi kepuasan oleh Allah terhadap apa yang diberikan kepadanya. (Diriwayatkan Muslim, At-Tirmidzi, Ahmad dan AlBaghawy) $)^{12}$.

\section{KERANGKA KONSEPTUAL}

\section{Kerangka Berpikir Konseptual}

Pemikiran konseptual (Conceptual Thinking) adalah kemampuan untuk mengidentifikasi pola atau hubungan yang tidak nampak dengan jelas. Termasuk di dalamnya menyimpulkan informasi yang beragam dan tidak lengkap menjadi

\footnotetext{
${ }^{10}$ Muhammad, Etika Bisnis Islam, (Yogyakarta: UPP AMP YKPN, 2004), 159.

${ }^{11}$ Philip Kotler dan Kevin Lane Keller, Manajemen Pemasaran, 56.

12. HR At-Tirmidzi, Ahmad dan Al-Baghawy
} 
sesuatu yang jelas, mengidentifikasi kunci atau dasar permasalahan di dalam situasi yang kompleksdan menciptakan konsep-konsep baru

\section{Paradigma Penelitian}

Dalam penelitian ini paradigma penelitian dikonsepsikan sebagai kerangka berpikir yang menjelaskan bagaimana cara pandang peneliti terhadap fakta kehidupan sosial dan perlakuan peneliti terhadap ilmu atau teori. Dalam hal ini paradigma penelitian juga menjelaskan bagaimana peneliti memahami suatu masalah, serta kriteria pengujian sebagai landasan untuk menjawab masalah penelitian.

\section{METODE PENELITIAN}

\section{Lokasi Penelitian}

Pemilihan lokasi penelitian ini dilakukan secara purposif atau sengaja, lokasi penelitian yaitu KJKS BMT NU Ngasem - Bojonegoro.

\section{Populasi dan Sampel Penelitian}

\section{Populasi}

Suharsimi Arikunto menjelaskan populasi adalah keseluruhan subyek penelitian. Apabila seseorang ingin meneliti semua elemen yang ada dalam wilayah penelitian, maka penelitiannya disebut populasi atau studi kasus. ${ }^{13}$

2. Sampel

Arikunto mengemukakan bahwa "sampel penelitian adalah sebagian atau wakil dari jumlah populasi yang diteliti". ${ }^{14}$

\section{Definisi konsep dan oprasional}

1. Variabel Bebas/Independent (X) yaitu variabel yang nilainya tidak tergantung pada variabel lain. Adapun menjadi variabel bebas dari penelitian ini adalah kualitas Produk, harga dan kualitas pelayanan.

\footnotetext{
${ }^{13}$ Suharsimi Arikunto, Prosedur Penelitian: Suatu Pendekatan Praktek, (Jakarta: Rineka Cipta, 2006), 130.

${ }^{14}$ Ibid., 131.
} 
2. Variabel Terikat/Dependent (Y)yaitu variabel yang nilainya tergantung pada variabel lain. Adapun yang terjadi variabel terikat adalah Kepuasan nasabah (Y) sebagai keseluruhan sikap yang ditunjukkan konsumen atas barang dan jasa setelah mereka memperoleh dan menggunakannya. ${ }^{15}$

\section{Teknik Pengumpulan Data}

Metode yang digunakan dalam penelitian ini yaitu:

1. Metode Observasi adalah "suatu teknik yang dilakukan dengan cara mengadakan pengamatan secara teliti serta pencatatan secara sistematis". ${ }^{16}$

2. Metode Angket adalah alat penelitian berupa daftar pertanyaan untuk memperoleh keterangan dari sejumlah responden. ${ }^{17}$

3. Metode Wawancara adalah suatu "dialog yang dilakukan oleh pewawancara untuk memperoleh informasi dari terwawancara". ${ }^{18}$

\section{Pengujian Statistik}

1 Uji Reliabilitas adalah alat untuk mengukur suatu kuesioner yang merupakan indikator dari variabel atau konstruk.

2 Uji Validitas adalah suatu ukuran yang menunjukan tingkat-tingkat kevalidan dan keabsahan suatu instrumen.

\section{Analisis Regresi Linear Berganda}

Dimaksudkan untuk mengetahui pengaruh/hubungan variabel bebas dengan terikat. Apakah masing-masing variabel independen berhubungan positi atau negatif. Selain itu, untuk memprediksi nilai dari variabel dependen apabila variabel independen mengalami kenaikan atau penurunan. ${ }^{19}$

\footnotetext{
${ }^{15}$ John C. Mowen dan Michael Minor, Perilaku Konsumen, Edisi Kelima, Jilid 2 (Jakarta: Erlangga, 2002), 89.

${ }^{16}$.Sugiono, Metode Penelitian Bisni......, 138.

${ }^{17}$.Bambang Prasetyo, Metode penelitian....., 135.

${ }^{18}$ Bambang Prasetyo, Metode penelitian......, 138.

${ }^{19}$ Duwi Priyanto, Mandiri Belajar SPSS (Yogyakarta: MediaKom, 2009), 73.
} 


\section{Uji Hipotesis}

a. Uji-F (Uji Serentak) ini digunakan untuk mengetahui apakah variabel independen secara bersama-sama berpengaruh secara positif dan signifikan terhadap variabel dependen. ${ }^{20}$

b. Uji-t (Uji Parsial) digunakan untuk menguji apakah dalam model regresi variabel independen secara parsial berpengaruh signifikan terhadap variabel dependen. $^{21}$

\section{PAPARAN DATA, UJI STATISTIK DAN PEMBAHASAN \\ Profil KJKS BMT NU Ngasem ${ }^{22}$}

KJKS BMT Nurul ummah ngasem - bojonegoro merupakan lembaga keuangan yang berprinsip syari'ah.BMT dalam aktifitas nya menghimpun dan mayalurkan dana dari/kepada anggota atau calon anggota dengan sistem mudhorabah,musyarokah,murobahah dan ba'i bisamanil ajil yang sah menurut syari'ah dan tidak bertentangan dengan peraturan perundang-undangan negara indonesia.

\section{Pembahasan Hasil Penelitian}

Setelah peneliti meneliti langsung pada nasabah BMT KJKS NU NgasemBojonegoro melalui penyebaran angket yang harus diisi oleh nasabah, maka tujuan yang dikemukakan dalam penelitian ini adalah untuk menjelaskan:

1. Dari tabel coefficients dapat diketahui bahwa Variabel kualitas produk murabahah mempunyai nilai thitung $(2,551)$ lebih besar dari tabel $(2,006)$, dengan Sig. 0,014 lebih kecil dari nilai probalitas 0,05 atau nilai Sig. $0,014 \leq 0,05$, maka $\mathrm{H}_{0}$ ditolak dan $\mathrm{H}_{\mathrm{a}}$ diterima, yang berarti variabel kualitas produk murabahah terdapat dampak pengaruh yang signifikan terhadap kepuasan nasabah di KJKS BMT NU Ngasem-Bojonegoro dan hasil hipotesis penelitian telah teruji.

Menurut Henard dan Szimanski bahwa "kualitas produk murabahah merupakan superioritas atau pembedaan yang lebih tinggi dibandingkan dengan tawaran competitor $)^{23}$.

\footnotetext{
${ }^{20}$ Ibid., 81.

${ }^{21}$ Duwi Priyanto, Mandiri..., 83.

22 . RAT Kjks Bmt Nu Ngasem - Bojonegoro Tahun 2011, hal. 9.
} 
Dalam Al-qur'an memberikan kepada kita semua petunjuk yang jelas dalam konsumsi. Islam mendorong kepada umatnya untuk mengunakan barangbarang yang baik dan bermanfaat demi memenuhi kebutuhan dan keinginanya. Hal ini sebagai mana yang dijelaskan dalam surat An-nahl ayat 114:

Maka makanlah yang halal lagi baik dan rizki yang telah diberikan Allah kepadamu, dan syukirilah nikmat Allah jika kamu hanya kepada-Nya saja menyembah ${ }^{24}$.

Kesimpulan dari ayat Al-qur'an diatas, kata yang digunakan barangbarang yang halal dan baik adalah segala sesuatu yang bersifat menyenangkan, baik dan halal berkualitas.

2. Dari tabel coefficients dapat diketahui bahwa Variabel harga mempunyai nilai $t_{\text {hitung }}(-0,732)$ lebih besar dari tabel $(-2,006)$, dengan sig.0,467 lebih besar dari nilai probalitas 0,05 atau nilai sig.0,467 $\geq 0,05$, maka $\mathrm{H}_{0}$ diterima dan $\mathrm{H}_{\mathrm{a}}$ ditolak,yang berarti variabel harga tidak ada dampak pengaruh yang signifikan terhadap kepuasan nasabah di KJKS BMT NU Ngasem-Bojonegoro dan hasil hipotesis penelitian telah teruji.

Dengan demikian maka secara parsial harga memberikan pengaruh positif bagi kepuasan nasabah. Konsep hrga dalam Islam dapat dirujuk kepada hadits Rasululllah Saw sebagaimana disampaikan oleh Anas RA, sehubungan dengan adanya kenaikan harga - harga barang di kota Madinah. Dalam hadits tersebut diriwayatkan sebagai berikut :

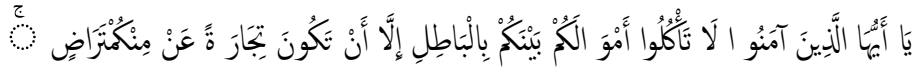

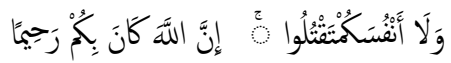

"Wahai orang-orang yang beriman! Janganlah kamu saling memakan harta sesamamu dengan jalan yang batil (tidak benar), kecuali dengan jalan perdagangan yang berlaku atas dasar suka sama-suka di antara kamu. Dan janganlah kamu membunuh dirimu. Sesungguhnya Allah Maha Penyayang kepadamu”.'(Hr.Abu Dawud.Ibn Majah Dan At-Tirmidzi) $)^{25}$

\footnotetext{
${ }^{23}$.enard, D.H. dan Szymanski, “Journal of Marketing Research” dalam D.M., 2001,"Why some new products are more successful than others",Journal of Marketing Research, Vol.XXXVIII August.(diakses tanggal 12 Oktober 2014 pukul 09.15)

${ }^{24}$. al-qur'an surat An-nahl ayat 114.

25 . Hr.Abu Dawud.Ibn Majah Dan At-Tirmidzi
} 
Dalam hadist diatas dalam haram bagi peguasa untuk menentukan harga karena itu adalah bentuk kedzaliman.

3. Daritabel coefficients dapat diketahui bahwa Variabel kualitas pelayanan mempunyai nilai thitung $(-0,015)$ lebih besar dari tabel $(-2,006)$, dengan sig.0,988 lebih besar dari nilai probalitas 0,05 atau nilai sig.0,988 $\geq 0,05$, maka $\mathrm{H}_{0}$ diterima dan $\mathrm{H}_{\mathrm{a}}$ ditolak,yang berarti variabel kualitas pelayanan tidak terdapat pengaruh yang signifikan terhadap kepuasan nasabah di KJKS BMT NU NgasemBojonegoro dan hasil hipotesis penelitian telah teruji.

Dalam hal ini menunjukkan bahwa kualitas pelayanan mampu meningkatkan kepuasan nasabah. Kinerja karyawan dalam pelayanan KJKS BMT Nurul Ummah Ngasem - Bojonegoro berupa Kendala (Reliability), Daya Tanggap (Responsiveness), dan kepedulian/Empati (emphaty) dianggap berpengaruh pada responden dalam menjawab pertanyaan-pertan yaan telah diberikan oleh peneliti.

karyawan memberikan perhatian yang bersifat pribadi kepada nasabahnya. Karyawan juga dituntut untuk memiliki kemampuan dalam memberikan pelayanan dengan baik. sesuai dengan yang dijanjikan. Sesuai dengan firman Allah dalam surat al Baqarah ayat 27 :

(yaitu) orang-orang yang melangar perjanjian Allah sesudah perjanjian iti teguh, dan memutuskan apa yang diperintahkan Allah (kepada mereka) untuk menghubungkannya dan membuat kerusakan di muka bumi. mereka Itulah orang-orang yang rugi. ${ }^{26}$

Ekonomi konvensional pilihan didasarkan atas selera pribadi masingmasing. Manusia boleh mempertimbangkan tuntunan agama, boleh juga mengabaikan. Sedangkan dalam ekonomi Islam, keputusan pilihan ini tidak dapat dilakukan semaunya saja, semua perilaku harus dipandu oleh Allah lewat AlQur'an dan Hadis.

4. Di antara keseluruhan variabel bebas yang diteliti dilakukan pengujian sendirirsendiri antara variabel $\mathrm{X}_{1}$ (kualitas produk murabahah), $\mathrm{X}_{2}$ (harga), $\mathrm{X}_{3}$ (kualitas pelayanan) dan variabel Y (kepuasan nasabah) yang paling dominan. Dari tabel ANOVA membuktikan bahwa yang paling berpengaruh atau dominan adalah kualitas produk murabahah. Kualitas produk murabahah merupakan variabel yang paling dominan terhadap kepuasan nasabah di KJKS BMT NU Ngasem-

26. Al-Qur'an surat Al Baqarah ayat 27 
Bojonegoro dibandingkan dengan harga dan kualitas pelayanan yang dimiliki, Karena $\mathrm{H}_{0}$ variabel kualitas produk murabahah ditolak $(<0,05)$ dengan $\mathrm{F}_{\text {hitung }}$ sebesar 7,684 karena variabel harga $\mathrm{H}_{0}$ variabel diterima $(>0,05)$ dengan $\mathrm{F}_{\text {hitung }}$ sebesar 1,385, dan karena $\mathrm{H}_{0}$ variabel kualitas pelayanan diterima $(>0,05)$ dengan $F_{\text {hitung }}$ sebesar 0,000 maka diantara ketiga variabel tersebut variabel yang paling dominan berpengaruh terhadap kepuasan nasabah adalah variabel kualitas produk murabahah. Karena variabel kualitas produk murabahah mempunyai nilai $F_{\text {hitung }}$ lebih besar dari variabel harga dan variabel kualitas pelayanan dan hasil hipotesis penelitian telah teruji.

Keputusan masyarakat (konsumen) terbentuk dari berbagai variabel yang mempengaruhi. Menurut pandangan islam mengenai perilaku konsumen dalam proses pengambilan keputusan dapat dilihat pada surat Al maidah ayat 100, yaitu:

Katakanlah: "tidak sama yang buruk dengan yang baik, meskipun banyaknya yang buruk itu menarik hatimu, Maka bertakwalah kepada Allah Hai orang-orang berakal, agar kamu mendapat keberuntungan."27

5. Di antara keseluruhan variabel bebas yang diteliti dilakukan pengujian sendirirsendiri antara variabel $\mathrm{X}_{1}$ (kualitas produk murabahah), $\mathrm{X}_{2}$ (harga), $\mathrm{X}_{3}$ (kualitas pelayanan) dan variabel Y (kepuasan nasabah) yang paling dominan. Dari tabel ANOVA membuktikan bahwa yang paling berpengaruh atau dominan adalah kualitas produk murabahah. Kualitas produk murabahah merupakan variabel yang paling dominan terhadap kepuasan nasabah di KJKS BMT NU NgasemBojonegoro dibandingkan dengan harga dan kualitas pelayanan yang dimiliki, Karena $\mathrm{H}_{0}$ variabel kualitas produk murabahah ditolak $(<0,05)$ dengan $\mathrm{F}_{\text {hitung }}$ sebesar 7,684 karena variabel harga $\mathrm{H}_{0}$ variabel diterima $(>0,05)$ dengan $\mathrm{F}_{\text {hitung }}$ sebesar 1,385, dan karena $\mathrm{H}_{0}$ variabel kualitas pelayanan diterima $(>0,05)$ dengan $F_{\text {hitung }}$ sebesar 0,000 maka diantara ketiga variabel tersebut variabel yang paling dominan berpengaruh terhadap kepuasan nasabah adalah variabel kualitas produk murabahah. Karena variabel kualitas produk murabahah mempunyai nilai $F_{\text {hitung }}$ lebih besar dari variabel harga dan variabel kualitas pelayanan dan hasil hipotesis penelitian telah teruji.

27. Al-Qur'an surat $\mathrm{Al}$ maidah ayat 100 
Dalam hal ini dikemukakan oleh American Society for Quality Contrl bahwa kepuasan pelanggan merupakan penilaian pelanggan terhadap penampilan barang dan jasa itu sendiri, apakah dapat memenuhi tingkat keinginan hasrat dan tujuan pelanggan.

Keputusan masyarakat (konsumen) terbentuk dari berbagai variabel yang mempengaruhi. Menurut pandangan islam mengenai perilaku konsumen dalam proses pengambilan keputusan dapat dilihat pada surat Al maidah ayat 100, yaitu:

Katakanlah: "tidak sama yang buruk dengan yang baik, meskipun banyaknya yang buruk itu menarik hatimu, Maka bertakwalah kepada Allah Hai orang-orang berakal, agar kamu mendapat keberuntungan." 28

\section{Kesimpulan}

Berdasarkan hasil penelitian yang telah dilakukan mengenai kepuasan nasabah KJKS BMT NU Ngasem-Bojonegoro, dapat disimpulkan bahwa:

1. Dalam uji t kualitas produk murabahah ada pengaruh yang signifikan terhadap kepuasan nasabah di KJKS BMT NU Ngasem-Bojonegoro dan hasil hipotesis penelitian telah teruji.

2. Dalam uji t Variabel tidak ada pengaruh yang signifikan terhadap kepuasan nasabah di KJKS BMT NU Ngasem-Bojonegoro dan hasil hipotesis penelitian telah teruji.

3. Dalam uji t kualitas pelayanan tidak ada pengaruh yang signifikan terhadap kepuasan nasabah di KJKS BMT NU Ngasem-Bojonegoro dan hasil hipotesis penelitian telah teruji.

4. Dalam uji F, menggambarkan bahwa kualitas produk murabahah, harga dan kualitas pelayanan tidak ada dampak pengaruh terhadap kepuasan nasabah di KJKS BMT Nurul Ummah Ngasem - Bojonegoro dan hasil hipotesis penelitian telah teruji.

5. Berdasarkan hasil di atas maka diketahui bahwa variabel yang paling dominan berdampak terhadap kepuasan nasabah adalah kualitas produk murabahah Karena variabel kualitas produk murabahah mempunyai nilai

28. al-qur'an surat Al maidah ayat 100 
Fhitung lebih besar dari variabel harga dan variabel kualitas pelayanan dan hasil hipotesis penelitian telah teruji.

\section{Daftar Pustaka}

.ManajemenPemasaran. Jakarta: PT. Prenhallindo, 2002

Arikunto, Suharsimi. Prosedur Penelitian: Suatu Pendekatan Praktek. Jakarta: Rineka Cipta, 2006.

Duwi Priyanto, Mandiri Belajar SPSS. Yogyakarta: MediaKom, 2009.

Enard D.H. dan Szymanski, "Journal of Marketing Research" dalam D.M., 2001,"Why some new products are more successful than others",Journal of Marketing Research, Vol.XXXVIII August.(diakses tanggal 12 Oktober 2014 pukul 09.15)

Fandy, Tjiptono dan Chandra ,Gregorius. Service, Citra Wisata dan Satisfaction. Yogyakarta: Andi, 2005.

Garvin dan Umar, Husein. Riset Pemasaran dan Perilaku Konsumen, Jakarta : PT Gramedia Pustaka Utama, 2003.

Kotler ,Philip. Marketing Management, $11^{\text {th }}$ Edition. New Jersey: Prentice Hall Int'l, 2003.

Lupiyoadi , Rambat dan Hamdani , A. Manajemen Pemasaran Jasa Edisi2. Jakarta: Salemba Empat, 2006.

Mowen ,John C dan Minor, Michael. Perilaku Konsumen, Edisi Kelima, Jilid 2. Jakarta: Erlangga, 2002.

Muhammad, Etika Bisnis Islam, Yogyakarta: UPP AMP YKPN, 2004.

Parasuraman, et.al. dan Lane Keller, Kevin. Manajemen Pemasaran, 56.

RAT KJKS BMT NU Ngasem - Bojonegoro Tahun 2011. 